\title{
Bilingual Education in Guatemala
}

\section{Adriana Soto-Corominas}

\begin{abstract}
Language shift is a phenomenon by which one language is lost and replaced by another one. This project focuses on the language shift process happening in Guatemala, a country where the majority language, Spanish, coexists with 24 Indigenous languages. The objective of this project was to assess the role and development of the Intercultural Bilingual Education (IBE) model, which was implemented with the aim of promoting a type of education that would integrate the cultures and languages of the country. In order to carry out this project, teachers from different schools and members of the government and of the Academy of Mayan Languages were contacted. Data were gathered by means of informal, semistructured interviews. After analyzing the data, it became clear that the IBE model was not being implemented as it was supposed to be and, therefore, the language shift process continues following its course in the country.
\end{abstract}

Keywords: language shift; bilingual education; Indigenous languages; Mayan languages; education

\section{Introduction}

Antonio de Nebrija (2011), in his prologue to Gramática de la lengua castellana [Grammar of the Castilian Language], asserted that language had always been the companion of empire (p. 13, my translation). Although an empire is somehow temporary, the linguistic destruction that it leaves, unfortunately, tends to have permanent consequences. The most widely spoken languages today, such as English, Spanish, and Portuguese, are the present-day traces of historical relationships of conquest and power (Austin, 2008).

Language and power have always had a close relationship. On many occasions, a language has been imposed by forbidding or discouraging the use of other languages. There exist all sorts of discouragements, which range from explicit prohibitions against certain languages, as in the case of the ban on publishing in Kurdish in Syria or the Francoist motto "One Flag, One Nation, One Language" in Spain, to subtler strategies, as in the use of only one language in mass media, the promotion of those who speak a certain language, or the ostracism of those who speak a different one. 
Prohibited or discouraged languages are known as minoritized languages, which is not to be confused with minority languages. The difference between the two terms is that the latter refers to languages that are spoken by a small number of people, whereas minoritized languages suffer discrimination or persecution. A minoritized language does not necessarily have to be a minority language, although this happens to be the trend. For example, during the conquest of the Americas, Spanish was the minority language but Indigenous languages rapidly became minoritized.

Regardless of how frequent minoritization is, the importance of preserving languages, and even of being multilingual, is commonly accepted and endorsed by the vast majority. Each and every language reflects a culture, a history, a wealth, a body of knowledge, and a way of perceiving the world that belong to the people who speak it. When a language is lost, all these elements are at risk of being lost, as well.

The process of losing a language is called language shift, since no language is lost without being replaced by a different one. According to the document Language Vitality and Endangerment by UNESCO (2003), a language is lost when it is used in fewer and fewer environments and is not transmitted to the next generation. But why would somebody not transmit his or her own language to the next generation? According to UNESCO (2003), there are external and internal causes. The external causes are those which are not related to the speakers, but to their environment, such as in cases of military or religious subjugation. Migration is also an important cause of language shift. In this case, migration should not only be understood as crossing the border into another country, but also as moving from a rural community to an urban one, where there are more possibilities and more jobs, but typically only one language.

Internal causes are those that arise from the speakers themselves (although these are commonly related to their environment). These are cases in which speakers might feel a certain pressure to abandon their language, stemming from a negative attitude of the people around them in respect to the language, or from the fact that these speakers identify their language with unfavorable social conditions. In such a scenario, the possibility of abandoning their language in favor of the majority one seems to be the only way to improve their living conditions and those of future generations. Frequently, together with this language loss, there is also a loss of the culture. Not as frequently, however, there may be an improvement in the living conditions despite these losses. Moreover, there is a misconception that worsens the situation: the idea that monolingualism is the default state. On many occasions, certain communities whose languages are endangered conceive of bilingualism as a transitory stage and assume language shift, that is, the ultimate replacement of their language by the more privileged one, as the only possible outcome (Sicoli, 2011, p. 161).

The question we ought to be asking, then, is how this situation can be prevented or amelioriated. Although it is true that it is the speakers who ultimately uphold or lose a language, there are a certain number of measures that must be 
taken that can aid in the preservation and recovery of languages. UNESCO (2003) proposes five main approaches to achieve this goal:

1. Basic linguistic and pedagogical training: teachers must be educated in basic linguistics and in the methodology of teaching and preparing materials.

2. Sustainable development in literacy and local documentation skills: speakers must be educated and should be able to document the language so that it can be studied in a more accessible manner.

3. Supporting and developing national language policy: all languages must be respected and included in national languages policies.

4. Supporting and developing education policy: support not only the teaching of minority languages but also their use as vehicular languages in education.

5. Improving living conditions and respect for the human rights of speaker communities.

In the implementation of these five points, three focus groups need to be drawn upon: speakers, teachers, and government. A large-scale linguistic change in a country is not and will not be likely if any of these three groups is against it. The aim of the present study is to examine the roles of these three groups, as well as their attitudes and motivations regarding the language shift that is currently taking place in Guatemala, a country where, for the last 20 years, the necessity of improving the vitality of their languages is being defended by the Government (or so it appears). In order to do so, we must first acknowledge the global situation of the country and its education system.

\section{Guatemala Before and During the Conquest}

In 1492, the first transatlantic encounters between Europe and the Americas took place. In all likelihood, these encounters had a great impact on both the conquerors and the conquered peoples, since each found themselves in very different historical moments. The conquerors imposed their customs, their social organization and, of course, their language. They also welcomed many advances in different areas of knowledge from the conquered peoples. The territories of present-day Guatemala (derived from Nahuatl Quauhtlemallan, land of many trees) had already given in to the Spaniards by 1530.

The Catholic Monarchs, especially Queen Isabella I, were the leaders behind the Conquest of the Americas, which came after the Spanish victory over the Moors and the reunification of Spain. Because of this, both Catholicism and the Spanish language played crucial roles in the new territories. One of the first phenomena that took place was mestizaje, the mix between the men sent from Spain and Indigenous women. This mix of cultures and races fostered the expansion of the Spanish language and Catholicism. With the arrival of Spanish women, mestizaje began to be viewed negatively and mestizos, those of mixed American and European ancestry, started to be marginalized. Juan de Solórzano y Pereira, a Spanish jurist of the 
sixteenth century, claimed that mestizos were despicable because "they are born out of adultery or out of other unions, always illicit and punishable, since there are few Spaniards of honor who marry Indians" (Traslosheros, 1994, p. 54; my translation). It appears, then, that racism was the order of the day at the beginning of the colonial period.

Population growth became the trend, with the mestizos (who would soon be called ladinos $^{1}$ ) being the group that increased the most in numbers. Some Indigenous communities, together with their languages, recovered from the damage suffered during the Conquest. Other communities, nevertheless, perished over that period of time (Luján Muñoz, 1999).

\section{Guatemala Today}

The Republic of Guatemala is administratively divided into 22 departments, each one headed by a governor appointed by the President of the Republic. Currently, Guatemala has a population of more than $15,000,000$. Approximately $40 \%$ of the entire population proclaim themselves Indigenous. This $40 \%$ is not equally spread throughout the country. In some departments, there are more than 95\% Indigenous people, as in Sololá or Totonicapán, whereas in other departments, there is no registered Indigenous group, as in El Progreso (Instituto Nacional de Estadística [INE], 2011).

The Indigenous $40 \%$ of Guatemala's inhabitants, however, does not reflect the reality of the country. It is estimated that the real figures go beyond this percentage by $20 \%$ (AECID, 2008). Since proclaiming oneself Indigenous, unlike in other countries, does not provide any social or economic benefits, many prefer to define themselves as ladinos to avoid prejudice (Sodepaz, 2011).

The ubiquitous discrimination against the Indigenous communities was aggravated by the Guatemalan Civil War (1960-1996) (Interamerican Comission of Human Rights [ICHR], 2003). During this period, an estimated 200,000 people disappeared or were killed. Of these, $90 \%$ of the crimes were committed by members of the military and the vast majority of the crimes (an estimated 98\%) were left unpunished (REMHI [Recuperación de la Memória Histórica], 1999). These were terrible crimes against the civil population, especially in the rural areas, since the intention was to prevent them from forming guerrilla groups. The Indigenous population was deeply affected by this conflict (Pablo \& Zurita, 2013). The language, always sensitive to any political conflicts, not only suffered the consequences of the war, but also became a reason for violence itself. Guatemala, Never Again! (REMHI, 1999), the result of a daring initiative by the Office of Human Rights of the Archbishop of Guatemala's Recuperation of Historical Memory, is a compilation of the personal stories of the victims of this conflict, such as these two:

\footnotetext{
${ }^{1}$ The term ladino designates the mestizo population of Central America who speak Spanish as a mother tongue. This term does not bear any relation to the language spoken by Sephardic Jews.
} 
And so there was a woman named Dominga; she was a Qeqchi. And they always ridiculed her because she didn't speak Spanish, or "Castilian" very well. Case 1280 (Kiche' man), Palob, Quiché, 1980. (REMHI, 1999, p. 48)

Rosa and her children can't speak their own language anymore; they have learned to speak other languages. Because of the violence they lost their tradition. Case 10004, Chacalté village, Chajul, Quiché, 1982. (REMHI, 1999, p. 48)

\section{The Linguistic Scenario in Guatemala}

Despite the difficulties, Guatemala is still a country with great cultural and linguistic richness. As of 2003, as Table 1 below shows, 25 languages were spoken, 22 of which were Mayan, together with Spanish, Garifuna and Xinka. ${ }^{2}$ Spanish is by far the most widely spoken language and is spoken by both ladinos and Indigenous people, both as a mother tongue and as a second language. Indigenous languages are scattered throughout the country, but are especially present in the central region (Richards, 2003).

\footnotetext{
${ }^{2}$ Garifuna is, strictly speaking, not a Guatemalan Indigenous language since it is the language spoken by the descendants of the African slaves who settled on the coasts of the Caribbean Sea. However, for the purpose of this project, Garifuna will be considered an Indigenous language, together with Xinka and the Mayan languages.
} 


\begin{tabular}{|c|c|c|}
\hline Language & Family & Speakers \\
\hline Spanish & Indo-European & $9.075 .469^{3}$ \\
\hline K'iché & \multirow{21}{*}{ Mayan } & 922.378 \\
\hline Q’eqchí & & 726.723 \\
\hline Kaqchikel & & 475.889 \\
\hline Mam & & 519.640 \\
\hline Q'anjob'al & & 99.211 \\
\hline Poqomchí & & 69.716 \\
\hline Ixil & & 69.137 \\
\hline Achi & & 51.593 \\
\hline Tz'utujil & & 47.669 \\
\hline Poptí & & 38.350 \\
\hline Chuj & & 38.253 \\
\hline Chalchiteko & & 35.000 \\
\hline Poqomam & & 9.548 \\
\hline Ch'orti' & & 9.105 \\
\hline Sipakapense & & 6.334 \\
\hline Akateko & & 5.572 \\
\hline Sakapulteco & & 3.940 \\
\hline Awakateko & & 1.272 \\
\hline Tektiteko & & 1.241 \\
\hline Uspanteko & & 1.231 \\
\hline Mopan & & 468 \\
\hline Garifuna & Arawaka & 203 \\
\hline Itzá & Mayan & 123 \\
\hline Xinka & Isolate & 18 \\
\hline
\end{tabular}

Table 1. Languages Spoken in Guatemala, Language Family and Number of Speakers of the Language as a Mother Tongue

Regardless of this enormous linguistic richness, article 173 of the current Constitution of Guatemala, which dates from 1993, considers only Spanish as the official language, relegating the others to being just vernacular: "Official language. The official language of Guatemala is Spanish. Vernacular languages are part of the cultural heritage of the Nation" (my translation). Nevertheless, article 76 expresses an interest in and obligation for bilingual education in specific areas of the country: "Education system and bilingual education. [...] Teaching should be preferably bilingual in those areas with a population that is predominantly Indigenous" (my translation).

\footnotetext{
${ }^{3}$ Spanish is not only the language with more native speakers but also the language that has more speakers of it as a second language. In the same census, the addition of speakers of Spanish as both L1 and L2 resulted in, roughly, $80 \%$ of the entire population of the republic using Spanish on some level.
} 


\section{Education}

Due to the extremely precarious economic situation of most of the Guatemalan population, especially in rural areas where resources are scarce and are typically intended for survival, education is considered a luxury, rather than an obligation or a right. Because of this, Guatemala is the country with the highest illiteracy rate in Latin America (SITEAL, 2010). Although the overall literacy rate is $76 \%$, this percentage varies significantly across the country. In the department of Guatemala, where the capital is situated and where the majority of the population is ladino, the literacy rate is $90 \%$. In contrast, in departments such as el Quiché or Alta Verapaz, which have a significant presence of Indigenous people, it barely reaches $60 \%$ (INE, 2011).

The formal education system in Guatemala has five basic levels, as shown in Table 2, some of which are optional and some of which are obligatory.

\begin{tabular}{|l|l|l|} 
& Level & Age \\
\hline $\mathbf{1}^{\text {st }}$ & Initial & $0-3$ \\
\hline $\mathbf{2}^{\text {nd }}$ & Preprimary & $4-6$ \\
\hline $\mathbf{3}^{\text {rd }}$ & Primary & $7-12$ \\
\hline $\mathbf{4}^{\text {th }}$ & Secondary - basic & $13-15$ \\
\cline { 2 - 3 } & Secondary - diversificado & $16-18 / 19$ \\
\hline $5^{\text {th }}$ & Higher & $19 / 20$ - onwards \\
\hline
\end{tabular}

Table 2. Guatemala's Education System

Students are required to complete preprimary, primary, and basic schooling. On the other hand, initial level and diversificado are not compulsory. In diversificado, which starts immediately following the basic level, students choose one of the possible paths: teaching, secretarial studies, accounting, sciences, or arts, among others. The purpose of the last two paths is to prepare students for university, whereas the first three allow students to enter the labor market with a diploma.

There are two main schooling options in Guatemala: public and private. Private schools have an abundance of resources, but their fees are far too prohibitive for the vast majority of Guatemalan families to afford. In the national standardized tests on reading and mathematical skills, private schools typically occupy the highest positions in the ranking, leaving public schools in the middle and lowest positions. For example, the mathematics tests in 2013 showed that the first public school was ranked $78^{\text {th }}$, while the second one was ranked $510^{\text {th }}$ (Ministry of Education of Guatemala, 2014). In contrast to private education, public education is entirely funded by the government and is free for its students. Since it is this public system that the majority of the Indigenous population attends, this will be the system on which this project will focus. 
While discussing the education system, the option of scholarships is worth mentioning. In regard to public schools, grants for school transportation and materials are available. In private schools, there are a number of available grants, as well, but they function differently. Private schools offer the opportunity of studying with a full or partial (50\%) grant to high-achieving students with references from teachers, but without the necessary resources to pay for their education. Each school dictates its own criteria for students to be awarded the grant, which tend to be very demanding. A number of international NGOs also provide excellent students in financial need with scholarships to pursue their studies until the diversificado level (COED Association, 2014).

According to article 74 of the Constitution of Guatemala (1993), children must attend school until they have completed the basic level. In spite of this, education in Guatemala faces several challenges.

\section{Challenges of the Guatemalan Education System}

Despite the three first education levels being obligatory, many children do not actually attend school for preprimary and basic levels. Those who live in rural areas do not have the opportunity to attend classes due to the very limited offerings of these two levels outside urban areas. Because of this, many children start primary school without having learned how to read and write. Although it is true that primary schools are significantly more present in rural areas than preprimary schools, the wide dispersion of the rural communities makes it very hard, if not impossible, for a school to be found in each village. This forces many children to walk daily to a nearby village in order to attend class. This becomes a problem in itself since this walk can constitute a danger to young children due to cars driving past them or even frequent kidnappings (Cawley, 2013).

School dropout rates are one of the greatest problems that Guatemalan schools face. Only $46.2 \%$ of young people between ages $12-15$ were enrolled in basic level schooling between 2008-2012 and unfortunately, there is no available data regarding the percentage of students who attended classes regularly (UNICEF, 2013). The reasons for dropping out of school can range anywhere from personal lack of interest to forced child labor.

The existing Labor Code of Guatemala, last updated in 1995, establishes the rules of labor and, according to article 32, does not prohibit child labor, although it regulates it: "Employment contracts involving youth under the age of 14 must be signed by their legal representatives and require the approval of the General Labor Inspectorate" (my translation).

Nevertheless, and although this is not reflected in the Labor Code, Guatemala ratified in 2011 the agreement of the International Labor Organization, whereby it is established that no child under the age of 15 is allowed to work (Indigenous, Peasant and Trade Unionist Movement of Guatemala, 2011). Despite this fact, 20\% of the children in Guatemala between ages 7-14 are already working, and a great number of children (approximately 12,000) already work at ages 5 and 6 for an average of 47 to 58 hours per week (Fundación Proniño, 2014). 
Child labor does not affect all of the population of Guatemala equally. Indigenous children living in rural areas are more prone to it than other children since they tend to be poorer and their families usually live on their own agricultural production. ${ }^{4}$

\section{The teachers}

The key to quality education is the professional training of teachers. Nevertheless, the teachers in Guatemala are not always adequately trained. Eligibility for primary and secondary school teachers consists of any of the following three criteria:

1. Teaching diploma through diversificado: this is obtained after a 3-year period of preparation as a teacher that begins at age 16. At the end of this period, students receive a diploma that allows them to work as a qualified teacher, which makes this option very attractive.

2. Bachelor's degree: this means three more years of university education.

3. Master's degree and PhD: these two types of higher education are highly infrequent in primary or secondary teachers and are more oriented towards university teaching.

The fact that the first option grants the right to enter the job market as a qualified professional makes it very appealing to young people. Therefore, the teaching diploma has become an option that many have chosen. In 2005, 15,050 teachers graduated from diversificado, of which only 1,839 were actually hired as teachers (USAID, 2011). It is worth mentioning that many of these young adults choose to pursue the teaching diploma in order to have access to a job that may allow them to fund their studies in higher education. This implies that teachers, besides lacking knowledge in didactics and methodology, might also lack the vocation for a teaching career.

Both public and private schools have monolingual and bilingual positions. If a teacher wishes to occupy a bilingual position, the candidate must pass a language exam. This exam contains oral and written components. The oral section of the exam asks candidates to either narrate a story or answer some basic questions. In the written section, candidates are asked to complete a translation exercise. Because of the simplicity of this exam, not all teachers occupying a bilingual position are necessarily fluent in the Indigenous language they teach (Save the Children, 2011, p. 14). Once a teacher occupies a bilingual position, he or she must be paid a monthly cash incentive, the so-called bonus for bilingualism, which is a monthly supplement of $10 \%$ of the teacher's basic salary (Ministry of Education of Guatemala, 2013b).

\footnotetext{
${ }^{4}$ It is estimated that $82 \%$ of the rural population lives in a state of poverty (Ministry of Education of Guatemala, 2009a).
} 


\section{Intercultural Bilingual Education (IBE)}

Bilingual education came into existence in different parts of Guatemala towards the end of the 1980s (Ministry of Education of Guatemala, 2013b). It grew with the intention of spreading a balanced bilingualism across Indigenous children and bringing them closer to education. In 1995, the Ministry of Education of Guatemala, through the newly established Directorate-General of Intercultural Bilingual Education (DIGIBE), started to regulate the country's bilingual education.

In 2000, DIGIBE drafted and passed the Intercultural Bilingual Education model (IBE), whereby the government established the new school curriculum and the new national language policies. According to the model, the new school curriculum, which is still in force, posits that students have to spend at least 4 hours per week learning the first language (L1). In addition, 2 hours have to be invested in the learning of the second language (L2), which can be either Spanish or the Indigenous language, depending on the school; and 2 more hours in the learning of the third language (L3), English. Apart from this, the current curriculum has the objective that, at the end of primary schooling, children demonstrate high-level linguistic competence in the three languages. More specifically, in the L2, students are supposed to know how to express their opinion, explain, clarify, organize ideas in texts and make use of a wide range of vocabulary (Ministry of Education of Guatemala, 2013a).

It was not until 2008 when the government, led by Álvaro Colom, carried out the first consultations in different department to uncover, at a practical level, the strengths and weaknesses of the IBE and how it was being implemented. Several schools, national and international organizations, students, parents and teachers took part in these consultations, which were reflected in the document Modelo Educativo Bilingüe e Intercultural [Bilingual and Intercultural Education Model] (Ministry of Education of Guatemala, 2009b).

The implementation of the IBE model was supposed to have a number of advantages. To start with, if children were educated in their own language or surrounded by their culture, there should be presumably more class attendance (Chevigny, 2007). On top of that, in the schools where this model was present, teachers would promote respect for and interest in non-Ladino cultures and would motivate intercultural relations. Moreover, job positions would be created that would benefit bilingual teachers.

Nevertheless, in the consultations carried out in 2008, many weaknesses in the model were detected. In the first place, the school dropout rate had not been reduced. In the second place, it became clear that the objectives of promoting culture, interculturality, respect and equality among ethnic groups had not been addressed in the classroom. In fact, the Ministry of Education of Guatemala (2009b) determined that "in the practice of the IBE, assimilationist, subtractive bilingualism remains present and focused on the Indigenous population, subsequently contributing to racist and discriminatory practices" (p. 13, own translation). 
In summary, the first decade of the IBE did not meet the initial expectations in terms of results. The government in power in 2008 considered improving the IBE model a priority but, so far, no consultations regarding the current application of the model have taken place. It is within this scenario that this study takes place.

\section{The Study}

The aim of this project is to investigate the linguistic situation in the education system of Guatemala. The main questions to be answered are whether the Indigenous languages of the country are still being minoritized, whether the language shift is happening at the same pace in different areas of the country and, crucially, whether the IBE model is being fulfilled. All of this takes into account the three aforementioned focus groups: teachers, speakers, and government.

All the information was collected through informal interviews. The selected schools were four public Official Co-Educational Rural Schools (EORMs) in four different villages or towns. Additionally, two teachers from the Academy of Mayan Languages of Guatemala (ALMG) and one representative of the Directorate-General of Intercultural Bilingual Education (DIGEBI) were also interviewed.

\section{Schools}

\section{El Rejón (Sacatepéquez)}

Although the vast majority of inhabitants in the small mountainous village of El Rejón, in the department of Sacatepéquez, are Indigenous, the permanence of the language, in this case Kaqchikel, is at risk. Currently, virtually no children and only a few adults speak the language.

Except for a weekly hour and a half class of Kaqchikel, all other classes are delivered in Spanish, since it is the native language of all of the students. The teachers who are in charge of this class, none of whom receives or has ever received the incentive cash payment from the government, are native bilinguals of Kaqchikel and Spanish.

Teachers explain that they have very limited resources in the classroom. They do not have appropriate materials for the students since the very few books they received are out of date or of a much higher level than that of the students. For example, they have sometimes received literature for adults of a very advanced or even native level. Students who only take 1 hour 30 minutes of this language per week are not able to read any of these books. The lack of suitable materials forces teachers to create their own or to purchase them with their own money.

Another difficulty teachers face is their lack of knowledge in teaching Kaqchikel. They claim that they are unprepared and have not been trained to take on the task of teaching a second language to students. This unpreparedness becomes even more evident when teachers are required to instruct more than 30 students at a time, which is the case for the Kaqchikel language classes in this school. This lack of training, together with the lack of the necessary tools, makes teachers use educational techniques that are hardly communicative or dynamic, 
such as repetition, copying, and drawing.

Children in this school typically start learning Kaqchikel during their first year of primary school and continue throughout, although the opportunity for studying it cannot be offered every year. Due to the lack of bilingual teachers, a drawing takes place at the beginning of every school year in order to determine in which grades Kaqchikel will be taught.

Upon completion of primary school, the majority of students have a very limited knowledge of basic vocabulary, expressions, and grammar rules. Therefore, their linguistic competence in the Indigenous language is, overall, extremely poor.

When asked about the reason for the observable language loss in the area, one teacher explains that that it is twofold. Firstly, there continues to be fear amongst the oldest generation in the village that their children and grandchildren may suffer the discrimination and humiliation that they themselves had been subject to. Secondly, the shame of the Indigenous people, even of the teachers, towards their own culture is still present. This often causes them to reject their customs and distinctive traits such as their traditional clothes and, of course, their language.

Regardless of this, the teacher claims that the youngest generation in the village shows an interest in and curiosity about the language that their grandparents and great-grandparents speak (or used to speak), and that they even reproach their parents for not teaching them the language. What they are not aware of, in all likelihood, is that their parents are not to blame for the break in language transmission. It was their parents' parents or even grandparents who made the decision not to transmit Kaqchikel to the following generation. However, what the attitude of the children seems to imply is that they are freeing themselves from the prejudices and fears that their parents had internalized.

\section{Quetzaltenango (Quetzaltenango)}

In one primary school in this town, Indigenous students coexist with ladinos in virtually equal measure. The linguistic situation in this school differs slightly from the previous one. The vehicular language is Spanish, since it is the native language for a little more than a half of the children; however, an Indigenous language, K'iche', is the mother tongue for the remainder of the students in the school. Although a great number of students speak K'iche' as a mother tongue, many deny any knowledge of it. Teachers think this is due to their embarrassment in front of their peers. The story behind this embarrassment, however, hardly differs from the one in the previous village. These children's parents or grandparents internalized the idea that speaking a Mayan language was a reason for being discriminated against and many decided not only to free their children from such a burden, but also to transmit the prejudices against the language. In Quetzaltenango, according to one of the teachers, there is the widespread idea that a person who speaks a Mayan language is backward and not competent in today's world. 
Only one and a half hours per week is dedicated to the teaching of K'iche', which is the same amount of time that is dedicated to the L3 (English). The number of students per class is notably smaller than that of the previous schoolapproximately 26 students in each class. The teaching techniques do not differ from the ones in the previous school, though: repetition, copying, and drawing. Like the school in El Rejón, teachers hardly receive any materials or opportunities to be trained as teachers of a second and third language. Similarly, none of the teachers here receive the incentive cash payment that they are supposed to receive.

\section{San José El Yalú (Sacatepéquez)}

The third school was in the small village of San José El Yalú, again in the department of Sacatepéquez. Unlike the previous schools, this one offers not only primary, but also preprimary schooling, and unlike the two previous communities, the transmission of the Indigenous language, again Kaqchikel, is almost $100 \%$ in this village. This means that most children in San José El Yalú are fluent bilinguals of Kaqchikel and Spanish. The few parents who decided not to speak Kaqchikel to their children did so because they thought the language would not be useful for their future. The other parents, always encouraged by the schoolteachers, think that their children's bilingualism will improve their chances of finding a job.

Although it is true that children in all grades are taught Kaqchikel daily, especially writing skills, most subjects are taught entirely in Spanish, with clarifications in the Mayan language. The decision to use Spanish for the subjects was made by the teachers, who thought that it was the most appropriate way to make their students totally competent in both languages.

Teachers in this school also have a lack of materials. In fact, the materials they received from the Directorate General of Intercultural Bilingual Education (DIGEBI) were not effective because they were not at the appropriate level for the students. Nevertheless, teachers claim to receive support from the DIGEBI and the Guatemalan Academy of Mayan Languages (ALMG) in the form of frequent training sessions.

Another difference between this school and the previous schools is that some teachers here receive the much-deserved incentive cash payment.

\section{Santo Domingo Xenacoj (Sacatepéquez)}

The last school was in the village of Santo Domingo Xenacoj, also in the department of Sacatepéquez. This village is one of the very few where preprimary is available, which is possible thanks to the intervention of an American nongovernmental organization. The Guatemalan government, in fact, only provides for one teacher in the school. This American NGO looks for funding to implement and promote what is referred to as early stimulation. Through early stimulation, children learn how to read and write before reaching primary school and, therefore, start from a more advanced point. The requisites that the NGO imposes on all teaching staff are to master both Spanish and Kaqchikel and to use both languages when speaking to 
students and their parents. Apart from this, a clear effort is made by this school to raise awareness among parents of the value of preserving and transmitting their language to their children and to convince them that Kaqchikel is not a backward language but that, on the contrary, it constitutes an enormous advantage. Indeed, this encouragement seems to work when looking at the figures of language transmission. Even immigrants who arrive to this village from different areas of the country show an interest in learning Kaqchikel.

The employees of this school are involved in other aspects besides education. In order to motivate their students to attend class, and taking into account that the vast majority of this village lives in poverty, a system was developed which allows the students to eat breakfast at the school. The NGO purchased lands around the school that they turned into vegetable gardens, thus creating a project that relies on the cooperation of children, parents, and teachers and that is currently working at its full potential. Everyone takes part by tending to the gardens once a week and the produce they yield are for students to eat.

\section{Institutions}

Guatemalan Academy of Mayan Languages (ALMG) (Guatemala)

The ALMG is an autonomous Guatemalan organization that regulates the Mayan languages spoken in the country. Although the ALMG has many offices around the country, it is headquartered in Guatemala City. The role of this institution is crucial in the sense that it occupies a privileged position between the Guatemalan government and other educational institutions. This academy is making great efforts to promote the knowledge and dissemination of Mayan cultures and languages. It is also responsible for teaching a Mayan language to recently graduated teachers so that they can occupy a bilingual position. In addition to that, it provides training to teachers who are interested in improving their teaching skills.

A teacher from the ALMG acknowledges the ambiguous role of the government in how it develops bilingual education in the country. He estimates that the IBE model is carried out at about only $5 \%$ of its potential. This means that only $5 \%$ of the current curriculum is met, that only $5 \%$ of the money which should be invested is actually invested, that there are only $5 \%$ of the bilingual teachers there should be, and that this education only reaches $5 \%$ of the schools it should reach.

He also admits that the incentive cash payment for bilingual teachers is not being distributed equitably. Most of those who should be receiving it are not, and others with the appropriate connections in the government are.

This is not the only flaw of the government regarding the issue of bilingual education. Another clear example, according to a member of the ALMG, is the sea of red tape that prevents the Ministry of Education from making use of its allocated budget, which, in turn, allows for an annual reduction of the allegedly underused budget. He also agrees with the view that bilingual teachers do not have the required knowledge of L2 teaching methodology and teaching skills, and that the Ministry of Education is not providing them with appropriate instruction. In other 
words, the government is not training teachers who are able or willing to take on the crucial task of teaching an L2 in the country. He finally concludes that the IBE model, designed as it is, cannot work, since it was initially designed in government offices, without knowing or taking into account the reality of the country and the options that it may offer.

When asked for possible paths of linguistic recovery in the country, his answer is clear-cut. The first step to be taken is to stop treating Guatemalan Indigenous communities as part of the country's heritage and to start treating them as living, contemporary communities. The second step is to promote the officialization of Indigenous languages and not to relegate them to vernacular languages. These languages should be normalized, they should be used in daily situations in public and official venues, they should appear on signs and advertisements, and they should be perceived as normal and vehicular languages. The attitude of the government with respect to bilingual education must change, as well. Immediate results of bilingual education cannot be expected. Most times, the results of this type of education are only apparent in the long run and the most significant result, the one that should really matter, is attitudinal, and so it is not easily quantifiable. After these changes are made, he claims, it is only a matter of effort and time before Indigenous languages regain social acceptance and, consequently, speakers.

\section{Directorate General of Intercultural Bilingual Education (DIGEBI) (Sacatepéquez)}

The last stop was the DIGEBI, which is part of the Ministry of Education. One of its members acknowledges that the government has a remarkable interest in defending and preserving Mayan languages that, unfortunately, not everyone in the country seems to share. They claim that a considerable amount of material is sent out to schools for bilingual teachers, especially paper, pens, and, in some cases, dictionaries and books. He says that the lack of bilingual teachers is to blame for the ineffectiveness of the IBE model because in areas where there are enough bilingual teachers, bilingual education works perfectly. In addition to that, he maintains that the incentive cash payment for bilingual teachers has not been implemented for five or more years, so nobody receives it nowadays.

It is hard to discern whether the words of this member of the DIGEBI are the result of a well-learned propaganda-driven account or of utter conviction, which, in turn, would reflect a profound ignorance of the current situation as it stands. In any case, it is undeniable that his words do not reflect the current state of the IBE model in any way.

\section{Conclusions}

The transatlantic encounters of 500 years ago did not bring good luck to the autochthonous languages of present-day Guatemala. After centuries of being minoritized, the Indigenous languages started to gain, at least apparently, political recognition around the 1980s. Nevertheless, after listening to different testimonies, it seems that this recognition is not as solid as it appears, and that Indigenous 
languages are still perceived as a negative identity trait. These languages are no longer being transmitted to children everywhere outright. This implies that the Indigenous languages of Guatemala are undergoing a process of language shift, although at a different pace in different areas of the country.

After talking to teachers of different schools and members of two important institutions, it goes without saying that the current law put forward by the IBE model is neither enforced nor obeyed the country. There are seven closely interrelated challenges to the IBE model. The first challenge is Guatemala's language policy, which minoritizes all languages except Spanish, and consequently supports subtractive bilingualism. The second problem is the lack of qualified bilingual teachers who can take on the task of teaching a second (or third) language. The third main problem is the lack of economic resources provided by the government, which prevents many children from having access to preprimary and basic education, hampers the creation and distribution of new materials and hinders the training of teachers. The fourth problem is the inefficient administration of the resources that do exist, as seen in how the incentive cash payment is distributed and the several bureaucratic difficulties in making use of the allocated budget for bilingual education. The fifth problem is the huge lack of materials that are appropriate to the level, age, and circumstances of the students. The sixth problem is an academic curriculum that is not implemented in reality. Its hours per week requirements are not met and its social and communicative aims are not dealt with, let alone attained. The last, and possibly most important, problem is the widespread disinterest in the preservation of these languages. Since many speakers of Indigenous languages think that their language lies at the root of their situation of inequality, inferiority, and marginalization, many of them perceive their language shift as a way of improving their living conditions.

If history has taught us anything, it is that language shift, before completed, is a reversible phenomenon, but reversing it is a long-term process in which society needs to become involved at all levels. This requires commitment, dedication, investment, and effort, but, above all, it requires great amounts of respect.

We have the right to be equal when difference diminishes us; we have the right to be different whenever equality decharacterizes us.

-Bonaventure de Souza Santos

\section{References}

AECID. (2008). Proyecto de Pueblos Indígenas [Project of Indigenous peoples]. Retrieved from http://www.aecid.org.gt/aecid/index.php?option=com content\&view=articl e\&id= 21\&Itemid=37

Austin, P.K. (Ed.) (2008). One thousand languages. Berkeley: University of California Press. 
Cawley, M. (2013, August 7). Niños robados en Guatemala para adopción ilegal y tráfico de órganos. [Kidnapped children in Guatemala for illegal adoptions and organ trafficking]. In Sight Crime. Retrieved from http://es.insightcrime.org/noticias-del-dia/ninos-robados-en-guatemalapara-adopcion-ilegal-y-trafico-de-organos

Chevigny, B. (2007, August 28). Bilingual-intercultural education aims to keep indigenous girls and boys in school. Retrieved from http://www.unicef.org/infobycountry/guatemala 40728.html

COED Association. (2014). Programa de becas [Grants program]. Retrieved from http://www.coeduc.org/es/programas/becas.html

Constitution of Guatemala. (1993). Arts. 58, 71, 76 and 143.

Fundación Proniño. (2014). Trabajo infantil en Guatemala [Child labor in Guatemala]. Retrieved from http://www.telefonica.com.gt/pronino/trabajoinfantil-en-guatemala/

Indigenous, Peasant and Trade Unionist Movement of Guatemala. (2011, June 10). Convenios de la OIT ratificados por Guatemala [ILO conventions ratified by Guatemala]. Retrieved from

http://www.movimientosicg.org/index.php?option=com k2\&view=item\&id =115: convenios-de-la-oit-ratificados-por-guatemala

Instituto Nacional de Estadística (INE). (2011). Encuesta Nacional de Condiciones de Vida 2011 [National survey about living conditions 2011]. Retrieved from http://www.wikiguate.com.gt/w/images/2/2d/Encovi Resumen 2011.pdf

Interamerican Comission of Human Rights (ICHR). (2003, December 29). La situación de los pueblos indígenas [The state of Indigenous communities]. Retrieved from http://www.cidh.oas.org/countryrep/Guatemala2003sp/capitulo4.htm

Labor Code of Guatemala. (1995). Art. 32. Retrieved from http://www.ilo.org/dyn/natlex/docs/WEBTEXT/29402/73185/S95GTM01. $\underline{\mathrm{htm}}$

Luján Muñoz, J. (1999) La conquista [The conquest]. En Historia General de Guatemala. Tomo II. Retrieved from http://fucude.org/hcg/books/

Ministry of Education of Guatemala. (2009a, September). Modelo Educativo Bilingüe e Intercultural [Intercultural Bilingual Education model]. Retrieved from https://www.mineduc.gob.gt/DIGEBI/documents/modeloEBI.pdf

Ministry of Education of Guatemala. (2009b). Dirección de Educación Bilingüe Intercultural [Directorate General of Intercultural Bilingual Education]. Retrieved from http://www.mineduc.gob.gt/DIGEBI/leyes.html 
Ministry of Education of Guatemala (2013a, October 31). Área de comunicación y lenguaje L2 -Nivel primario [Communication and language in L2 - Primary level]. Currículum Nacional Base. Retrieved from http://cnbguatemala.org/index.php?title=Área de Comunicación y Lenguaj e_L_2__Nivel_Primario

Ministry of Education of Guatemala. (2013b, November). Educación Bilingüe en Guatemala [Bilingual education in Guatemala]. Retrieved from http://www.mineduc.gob.gt/DIGEBI/

Ministry of Education of Guatemala. (2014). Resultados nacionales 2013 [2013 national results]. Retrieved from www.s21.com.gt/mineduc/Resultados Nacionales 2013.xls

Nebrija, A. de (2011). Gramática de la lengua castellana [Grammar of the Castilian Language]. Linkgua digital.

Pablo, 0. de, \& Zurita, J. (2013, April 15). Las heridas de Guatemala [The wounds of Guatemala]. El País. Retrieved from http://elpais.com/elpais/2013/04/15/eps/1366020076 807356.html

REMHI (Recovery of Historical Memory Project). (1998). Guatemala, never again. Ciudad de Guatemala: Oficina de Derechos Humanos.

Richards, M. (2003). Atlas lingüístico de Guatemala [Linguistic atlas of Guatemala]. Retrieved from http://www.liceosiglo21.com/IDIOMA20MAYA/atlas/Atlas\%20Ling\%FC\% EDstico.pdf

Save the Children and Instituto Centroamericano de Estudios Fiscales (ICEFI). (2011, January 1). La educación bilingüe en Guatemala: Logros, desafíos y oportunidades [Bilingual education in Guatemala: Achievements, challenges and opportunities]. Retrieved from

http://www.wikiguate.com.gt/w/images/0/09/Educacion Bilingue en Guatemala.pdf

Sicoli, M.A. (2011). Agency and ideology in language shift and language maintenance. In T. Granadillo \& H.A. Orcutt-Gachiri (Eds.), Ethnographic contributions to the study of endangered languages (pp. 161-176). Tucson: The University of Arizona Press.

SITEAL. (2010, November). El analfabetismo en América Latina, una deuda social [Illiteracy in Latin America, a social debt]. Retrieved from http://www.siteal.iipeoei.org/sites/default/files/datodestacado furosevich 20101130.pdf

Sodepaz. (2011, March). Entrevista a Marta Casaus sobre el racismo en Guatemala [Interview with Marta Casaus about racism in Guatemala]. Retrieved from http://www.sodepaz.org/america-latina-mainmenu-15/guatemalamainmenu-37/1547-entrevista-a-marta-casaus-sobre-el-racismo-enguatemala.html 
Traslosheros H., J.E. (1994). Estratificación social en el reino de la Nueva España, siglo XVII [Social stratification in the kingdom of New Spain, seventeenth century]. Relaciones, 15(59), pp. 45-64.

UNICEF. (2013, December 26). At a glance: Guatemala. Retrieved from http://www.unicef.org/infobycountry/guatemala statistics.html

UNESCO. (2003, March 12). Language vitality and endangerment. Document submitted to International Expert Meeting on UNESCO Programme Safeguarding of Endangered Languages. Retrieved from http://www.unesco.org/new/fileadmin/MULTIMEDIA/HQ/CLT/pdf/Langua ge vitality and endangerment EN.pdf

USAID. (2011, August). El futuro laboral para los egresados de magisterio en Guatemala [The future with regard to work for recent teaching graduates]. Reforma educativa en el aula [Education reform in the classroom]. Retrieved from http://www.reaula.org/publicaciones.php 